\title{
Correction to: Carbon Derived from Sucrose as Anode Material for Lithium-Ion Batteries
}

\author{
RAHUL KUMAR, ${ }^{1,2,4}$ K. ANISH RAJ, ${ }^{1,3}$ SAGAR MITRA, ${ }^{1,3}$ \\ and PARAG BHARGAVA ${ }^{1,2}$ \\ 1.-National Centre for Photovoltaic Research and Education (NCPRE), Indian Institute of \\ Technology Bombay, Mumbai 400076, India. 2.-Department of Metallurgical Engineering and \\ Materials Science, Indian Institute of Technology Bombay, Mumbai 400076, India. \\ 3.-Department of Energy Science and Engineering, Indian Institute of Technology Bombay, \\ Mumbai 400076, India. 4.—e-mail: kumarrahul003@gmail.com
}

\section{Correction to:}

Journal of Electronic Materials

https://doi.org/10.1007/s11664-019-07567-y

In the original article, Sagar Mitra's last name is spelled incorrectly. It is correct as reflected here.
Publisher's Note Springer Nature remains neutral with regard to jurisdictional claims in published maps and institutional affiliations. 